\title{
Heterotopias borgeanas e a estética de Vitor Ramil
}

\author{
Cinara Ferreira ${ }^{1}$ \\ Carlos Walter Soares ${ }^{2}$ \\ ¿Por qué persistes, incesante espejo? \\ ¿Por qué duplicas, misterioso hermano, \\ el menor movimiento de mi mano? \\ ¿Por qué en la sombra el súbito reflejo? \\ Jorge Luis Borges
}

\begin{abstract}
This work proposes an aproximation between the poetics of Brazilian singer-songwriter and writer Vitor Ramil and Argentinian writer Jorge Luis Borges. Its objective is to examine the presence of themes and traces of Borges's writing in Ramil's artistic and essayistic production, in regard to the representation of space, especially taking Foucault's notion of heterotope into account. Thus, we intend to show how much the aesthetics of the artist proposes continuity to the proposal of Jorge Luis Borges, a writer which is considered a precursor in the representation of questions concerning postmodernity.
\end{abstract}

Keywords: Jorge Luis Borges; Vitor Ramil; heterotope; literature; music.

Resumo: Este ensaio propõe uma aproximação entre as estéticas do cantautor e escritor brasileiro Vitor Ramil e do escritor argentino Jorge Luis Borges. O objetivo é examinar a presença de temas e traços da escritura de Borges na produção artística e ensaística de Ramil, no que se refere à representação de espaços, considerando especialmente a noção de heterotopia de Michel Foucault. Desse modo, pretende-se mostrar o quanto a estética do artista propõe uma continuidade à proposta de Jorge Luis Borges, escritor considerado precursor na representação de questões da pós-modernidade.

Palavras-chave: Jorge Luis Borges; Vitor Ramil; heterotopia; literatura; música.

Introdução

A literatura de Jorge Luis Borges é reconhecida por sua importância na pós-modernidade, sendo fundamental na formação de escritores do século XX em todo o mundo. No Brasil, em especial no Rio Grande do Sul, observa-se em diferentes esferas artísticas um diálogo com o escritor argentino, no que se refere à representação do pampa e das questões do gaúcho, entre outros aspectos. Neste ensaio, propõe-se a análise de canções e textos do cantautor e escritor brasileiro Vitor Ramil, buscando uma aproximação com aspectos da poética de Borges. O propósito é examinar a presença de temas e traços do escritor argentino

1 Professora Adjunta do Departamento de Linguística, Filologia e Teoria Literária, UFRGS. Doutora em Literatura Comparada pela UFRGS.

2 Professor Adjunto do Curso de Música, UFPel. Doutor em Música pela UFRGS. 
na produção artística e ensaística do artista brasileiro, partindo do exame da representação dos espaços, sob a perspectiva dos estudos sobre heterotopia de Michel Foucault.

Além de referências diretas, a obra de Vitor Ramil apresenta afinidades estéticas, temáticas e estilísticas com a do escritor argentino como, por exemplo, o uso frequente de duplicações que repercutem em suas representações da identidade e na discussão sobre o local e o universal. Nesse sentido, os espaços representados pelos dois artistas remetem aos conceitos de utopia e heterotopia, propostos por Michel Foucault no prefácio de $A s$ palavras e as coisas. O teórico afirma que sua obra nasceu da leitura de um texto de Jorge Luis Borges. Trata-se de "O idioma analítico de John Wilkins", do livro Outras inquisições, em que o escritor adverte que "não há classificação do universo que não seja arbitrária e conjectural” (BORGES, 2007, p. 124). Ante essa afirmação, Foucault relata seu desconcerto ao se dar conta de que pior que as classificações arbitrárias e ilógicas é "a desordem que faz cintilar os fragmentos de um grande número de possíveis ordens na dimensão, sem lei nem geometria, do heteróclito” (2000, p. 8).

$\mathrm{Na}$ reflexão sobre a necessidade humana de nomear e ordenar, Foucault contrapõe os espaços das utopias e das heterotopias, modalidades que serão discutidas mais tarde na conferência "Outros espaços". Ao propor o espaço como centro das preocupações contemporâneas, o filósofo enfatiza que as utopias são espaços invertidos e irreais (como o paraíso do cristianismo), enquanto que as heterotopias são utopias realizadas, espaços reais em que outros espaços podem se encontrar (como os jardins, as colônias jesuíticas e de imigrantes, as casas de repouso, as festas e as feiras populares). Em As palavras e as coisas, Foucault ressalta:

As utopias consolam: é que, se elas não têm lugar real, desabrocham, contudo, num espaço maravilhoso e liso; abrem cidades com vastas avenidas, jardins bem plantados, regiões fáceis, ainda que o acesso a elas seja quimérico. As heterotopias inquietam, sem dúvida porque solapam secretamente a linguagem, porque impedem de nomear isto e aquilo, porque fracionam os nomes comuns ou os emaranham, porque arruínam de antemão a "sintaxe", e não somente aquela que constrói as frases - aquela, menos manifesta, que autoriza "manter juntos" (ao lado e em frente umas das outras) as palavras e as coisas. (2000, p. 8).

Foucault associa as utopias às fábulas e aos discursos, pois os mesmos se encontram na linha reta da linguagem, na dimensão fundamental da fábula, enquanto as heterotopias (como as que com tanta frequência se encontram em Borges) dessecam o propósito, detêm as palavras em si mesmas, desafiam desde sua raiz toda possibilidade de gramática (2000, p. 8). Entre as utopias e as heterotopias, entretanto, pode existir uma experiência de união ou mescla análoga à do espelho. Para Foucault, o espelho é, ao mesmo tempo, uma utopia e uma heteropia já que é um lugar sem lugar algum que existe na realidade e exerce uma espécie de contra-ação à posição ocupada diante do espelho (1967, p. 3).

A obra de Borges, nesse sentido, está repleta de lugares que refletem outros lugares, traço assimilado por Vitor Ramil em suas canções e escritura. O espelho é um símbolo determinante no enredo de contos borgianos como "Tlön, Uqbar, Orbis Tertius", de Ficções, e "O outro", do Livro de areia. No primeiro, Borges aponta o espelho como uma presença atroz por sua capacidade de multiplicação de imagens: 
Devo à conjunção de um espelho e de uma enciclopédia o descobrimento de Uqbar. (...) Do fundo remoto do corredor, o espelho nos espreitava. Descobrimos (na alta noite essa descoberta é inevitável) que os espelhos têm algo de monstruoso. Então Bioy Casares lembrou que um dos heresiarcas de Uqbar declarara que os espelhos e a cópula são abomináveis, porque multiplicam o número dos homens. (1999, p. 29)

No conto "O outro", diante de um rio, imagem análoga ao espelho, Borges "maduro" encontra-se com Borges jovem em um banco que remete a dois lugares/tempos distintos. María Izabel Zwanck, no artigo "Borges y su literatura en espejo", faz uma série de considerações sobre as recorrentes duplicações presentes nos textos do escritor argentino. A autora assinala que "el espejo goza de las dos virtudes paradójicas: presente/pasado, original/copia, develamiento/ocultación, identidad/alteridad. Juegos, simetrías, duplicaciones, fantasmas, repeticiones cíclicas e variaciones atraviesan la obra de Borges, e siguen bifurcándose en el lector atento a la manera de sus famosos senderos" $(2008$, p. 125).

\title{
Uma estética heterotópica
}

Vitor Ramil nasceu em 1962, em Pelotas, Rio Grande do Sul, ${ }^{3}$ cidade retratada em suas canções e livros como Satolep (palavra espelhada de Pelotas). Satolep é o título de uma de suas canções mais autobiográficas e também intitula um de seus romances. Ainda que Ramil seja um artista com influências musicais e literárias das mais diversas, sua obra está marcada pela cor do sul e sua geografia. Sua produção, com uma profundidade poética e musical raras, reflete várias influências, passando do rock ao erudito e revelando um artista complexo e comprometido com a contemporaneidade. Na hipnótica canção "Estrela, estrela” (1981), o autor já antecipa uma veia lírica ímpar no cenário da canção brasileira:

\author{
Estrela, estrela \\ Como ser assim \\ Tão só, tão só \\ E nunca sofrer \\ Brilhar, brilhar \\ Quase sem querer \\ Deixar, deixar \\ Ser o que se é \\ No corpo nu \\ Da constelação \\ Estás, estás \\ Sob uma das mãos \\ Evais e vens \\ Como um lampião \\ Ao vento frio \\ De um lugar qualquer
}

3 Seu trabalho compõe-se de dez discos, três romances e um ensaio. 
FERREIRA, Cinara e SOARES, Carlos W.

É bom saber

Que és parte de mim

Assim como és

Parte das manhãs

Melhor, melhor

É poder gozar

Da paz, da paz,

Que trazes aqui

Eu canto, eu canto

Por poder te ver

No céu, no céu

Como um balão

Eu canto e sei

Que também me vês

Aqui, aqui

Com essa canção

Quando viveu no Rio de Janeiro, cidade ao sudeste do Brasil, Ramil elaborou o conceito de estética do frio, instigado, entre outros motivos, pela estranheza que o frio provocava aos habitantes do resto do país. Deu-se conta, nessa época, de uma estética brasileira vinculada ao calor, que não abarcava parte considerável da produção artística do Sul, fortemente influenciada pelo frio. $\mathrm{O}$ autor passou a ver o frio como metáfora amplamente definidora do "gaúcho" (RAMIL, 2004), acercando o Rio Grande do Sul muito mais aos países do Cone Sul que às demais regiões do Brasil. Conforme Luis Augusto Fischer, a criação estética do Sul, por ser menos eufórica e mais elíptica, se aproxima do mundo gerado esteticamente em Montevideo e Buenos Aires; assim, o frio ganha direito à existência com o argumento do ensaio A estética do frio (FISCHER, 2013, p.11).

Das reflexões sobre pertencimento, clima e geografia, surge, em 1997, o disco Ramilonga. Nesse trabalho, composto por milongas, a canção "A milonga das sete cidades" define a estética do frio, a partir de sete características, expressas assim na letra da canção:

Fiz a milonga em sete cidades

Rigor, Profundidade, Clareza

Em Concisão, Pureza, Leveza

E Melancolia

Milonga é feita solta no tempo

Jamais milonga solta no espaço

Sete cidades frias são sua morada

Cada uma das características se define, metaforicamente, como uma cidade fria. Sobre os conceitos de concisão, pureza, leveza e melancolia, por exemplo, a letra da canção diz:

Concisão tem pátios pequenos

Onde o universo eu vi

Em pureza fui sonhar

Em leveza o céu se abriu 
Em melancolia minha alma

Me sorri e eu me vi feliz

O ensaio A estética do frio, assim como as canções e os romances de Ramil, dialoga diretamente com a obra de Jorge Luis Borges, considerada chave para pensar a literatura do século XX, com repercussões e ecos até hoje (OLMOS, 2016, p. 1). Na mesma linha da ideia desenvolvida por Borges em "El escritor argentino y la tradición", segundo a qual não é necessário que o escritor fale de gaúchos nem de pampa para que seja argentino (BORGES, 1974, p. 269), Ramil se constitui como um artista "gaúcho" que não se restringe a falar somente do Sul e suas peculiaridades, abordando vários temas e seguindo diversas direções em seus textos. De acordo com Fischer:

Borges, na juventude, despois de viver durante anos na Europa, volta a sua Buenos Aires e descobre que o universo se dá a conhecer não somente nas grandes tradições, nos temas tidos como superiores, nos cenários já consagrados, mas em qualquer parte, no rasgueado de um toque de guitarra, no casario irregular de um subúrbio, na pequena tragédia provinciana (2013, p. 10).

Ramilonga (1997), na percepção de Celso Loureiro Chaves, é um álbum rigoroso na pureza musical da milonga, sendo o trabalho em que o compositor reflete de forma primorosa a discussão pós-moderna, e borgiana, das conexões entre o local e o universal (CHAVES, 2013, p. 301). Ao lado de milongas com letras de Ramil, o disco também apresenta milongas compostas com versos de Fernando Pessoa ("Noite de São João"), João da Cunha Vargas ("Deixando o Pago" e "Último Pedido") e um poema do folclore uruguaio ("Milonga"). Compõe o mosaico sonoro e visual desse disco a citadina canção "Ramilonga", que dá seu título ao $\mathrm{CD}$, cheia de imagens da cidade de Porto Alegre no inverno do sul e a milonga "Indo ao pampa", que apresenta uma viagem imaginária entre o futuro e o passado, a tradição e a contemporaneidade:

Eu indo ao pampa

O pampa indo em mim

Diz um capitão:

"Seja bem vindo, hombre

Nosso tempo é todo teu

Tempo de morte, dor e fome

Mas tempo de pelear

Onde as ideias

Não são cegas sem ar

Só vou te pedir

A montaria, exausta

Não consegue mais andar

Que a partir de agora

Seja nosso o carro em que estás

Pois só um carro são

Nos pode levar" 
E lá vamos nós

Seguindo a frente fria

Pampa a dentro e através

Séculos XIX e XXI fundidos sob o céu

Que estende tanta luz

No campo rubro a meus pés

Eu acho que é bem

Eu indo ao pampa

O pampa indo em mim

Misturando inusitados timbres sonoros com a milonga, "Indo ao pampa" evoca o conto "O sul", de Borges, em que a identidade do homem da cidade é modificada pelo adentramento no pampa e pela visão da imagem de um gaúcho que, como um espelho, reflete o passado e o modo de ser inerente ao lugar:

Entre palavras ofensivas e obscenidades, atirou para o ar um facão, seguiu-o com os olhos, aparou-o, e convidou Dahlmann a brigar. O proprietário objetou com trêmula voz que Dahlmann estava desarmado. Nesse instante, algo imprevisivel ocorreu.

De um canto, o velho gaúcho estático, no qual Dahlmann viu um signo do Sul (do Sul que era seu), atirou-lhe uma adaga desembainhada que veio cair a seus pés. Era como se o Sul tivesse resolvido que Dahlmann aceitasse o duelo. (BORGES, 1999, p. 165).

As atmosferas representadas no conto e na canção se aproximam pela sugestão de entrecruzamento de tempos e espaços desencadeado pela visita do homem urbano ao pampa:

Também o vagão era diferente; não era o que tinha sido em Constitución, ao deixar a plataforma: a planície e as horas o haviam atravessado e transfigurado. Fora, a móvel sombra do vagão alongava-se em direção ao horizonte. Não turbavam a terra elementar nem povoações, nem outros sinais humanos. Tudo era vasto, mas ao mesmo tempo era íntimo $e$, de alguma maneira, secreto. No campo desmedido, às vezes não havia nada a não ser um touro. A solidão era perfeita e talvez hostil, e Dahlmann pôde suspeitar que viajava ao passado e não só ao Sul (BORGES, 1999, p. 163).

Em 2010, o compositor retoma as milongas em um trabalho intitulado Délibáb, palavra húngara que significa "ilusão do sul", ou seja, uma ilusão de ótica, um efeito visual, um espelhamento. No texto incluído no encarte do CD, Ernesto Sábato indica que "Único em seu gênero, este tipo de espelhismo transporta paisagens muito distantes a horizontes quase desérticos, reproduzindo ante os olhos maravilhados do observador, em dias de calor, o desenvolvimento de cenas distantes. Quadros curiosíssimos que cobrem o horizonte em enormes projeções. E suas imagens são planas, nunca invertidas, nítidas, claríssimas."

Nesse disco, Ramil apresenta doze milongas, seis em espanhol e seis em português, compostas com poemas de Jorge Luis Borges e João da Cunha Vargas. Esse trabalho foi gravado em Buenos Aires com a participação do violonista argentino Carlos Moscardini. De Borges, foram musicados alguns dos textos de Para las seis cuerdas, livro que reúne milongas, um gênero apreciado pelo autor. Ao compor suas melodias, Ramil atende ao convite feito por Borges no prefácio desta obra: "En el modesto caso de mis milongas, el 
lector debe suplir la música, ausente por la imagen de un hombre que canturrea, en el umbral de su zaguán o en un almacén, acompañándose con la guitarra. La mano se demora en las cuerdas y las palabras cuentan menos que los acordes" (BORGES, 1974, p. 953).

Entre os poemas de Borges musicados por Ramil, está a "Milonga de los hermanos", que remete ao passado mítico do gaúcho, nas figuras dos irmãos Iberra:

Traiga cuentos la guitarra

De cuando el fierro brillaba,

Cuentos de truco e de taba,

De cuadreras e de copas,

Cuentos de la costa brava

E el camino de las tropas.

Venga una historia de aeer

Que apreciarán los mais lerdos;

El destino no hace acuerdos

E nadie se lo reproche -

Ea estoe viendo que esta noche

Vienen del sur los recuerdos.

Velae, señores, la historia

De los hermanos Iberra,

Hombres de amor e de guerra

$E$ en el peligro primeros,

La flor de los cuchilleros

Ea hora los tapa la tierra.

Suelen al hombre perder

La soberbia o la codicia:

También el coraje envicia

A quien le da noche e día

El que era menor debía

Mais muertes a la justicia.

Cuando Juan Iberra vio

Que el menor lo aventajaba,

La paciencia se le acaba

E le armó no sé qué lazo

Le dio muerte de un balazo,

Allá por la costa brava.

Sin demora e sin apuro

Lo fue tendiendo en la vía

Para que el tren lo pisara.

El tren lo dejó sin cara,

Que es lo que el maeor quería.

Asi de manera fiel

Conté la historia hasta el fin;

Es la historia de Caín

Que sigue matando a Abel.

(BORGES, 1974, p. 955-956) 
Fischer destaca que Ramil é um caso admirável para a cultura brasileira por haver explicitado alguns dos nexos entre os universos dos países do Prata e o Brasil, os quais, de alguma forma, convergem na cultura cotidiana do Rio Grande do Sul (2013, p. 8). No álbum Délibáb, como referimos anteriormente, o título remete à ideia de espelho, espelhamento, ilusão de ótica. O disco compõe-se de poemas de Borges e Vargas, que aparecem alternados nas canções. Como um espelho, os poemas musicados tematizam o pampa, a cor local, a identidade do homem do Sul, colocando o gaúcho do Rio Grande do Sul diante do gaucho argentino, assim como o passado mítico do Sul diante dos tempos atuais. Nas palavras de Vitor Ramil, as milongas que havia composto para os versos de Borges e Vargas documentam a projeção de imagens remotas de arrabaldes de Buenos Aires e arremedos pampeanos na urbanidade de nossos tempos (DVD).

A duplicação também está presente em letras de canções de Ramil que não tratam diretamente do pampa, como em "A resposta" do disco À beça (1995). Nessa canção, uma estação de trem, talvez não por acaso o mesmo cenário do conto "O sul”, de Borges, define-se como um ponto que aglutina chegadas e partidas de sujeitos solitários:

O homem caminha só na estação

Vindo de todo trem de todo lugar

Chega na banca e olha o jornal

Tira do bolso o último cigarro

Ri da notícia antes de ler

Rindo se esquece o que ia fazer

Olha o cigarro solto na mão

Bota outra vez no bolso

Sem perceber

No espaço heterotópico da estação, o homem tropeça e segura o braço de uma mulher desconhecida, a quem faz uma pergunta que, tornando-se parte do refrão da canção, sugere o questionamento do homem contemporâneo sobre seu lugar no mundo (Que lugar é esse?):

Dá um passo em falso

E pega o braço de uma mulher que passa

E pergunta pra ela

E pergunta sem parar:

Que lugar é esse?

Que lugar é esse?

Ainda que a mulher não responda à pergunta, o encontro com o homem da estação produz um efeito epifânico sobre ela, enquanto ocupa seu lugar no trem que se desloca. No processo de duplicação, ao chegar em casa, a mulher faz a mesma pergunta a outro homem (supostamente seu marido), que não lhe diz nada:

Lá num vagão com gente demais

Pensa que tudo é doido nessa vida

Ri da resposta que ia dar

Rindo se esquece o que ia falar

Enche a paisagem com seu olhar

Passa com ela e vê que ficou lá atrás

Chega em casa calada 
E senta com um cara que não diz nada

E pergunta pra ele

E pergunta sem parar:

Que lugar é esse?

Que lugar é esse?

A pergunta sem resposta sugere a solidão do sujeito errante, vivida tanto em lugares de passagem onde se entrecruzam as multidões como na intimidade da casa, locus em que as pessoas, apesar de próximas, podem se desencontrar. O tema da solidão já está presente desde o primeiro disco de Vitor Ramil. Para Fischer, suas canções e romances apresentam sempre figuras de um homem desgarrado do movimento geral, atento a seus próprios passos e na busca de seu lugar na vida (2013, p. 9). O tratamento do tema da solidão em Ramil revela mais uma forte conexão com a ficção de Borges, profusa na representação da experiência fragmentada e dos espaços heterotópicos.

No conto "O Aleph" (1949), por exemplo, o protagonista se vê ante um ponto onde é possível ver todos os outros pontos do universo. Localizado no sótão de um casarão, em Buenos Aires, a ser demolido, este ponto recebe o nome de Aleph. ${ }^{4}$ A sobreposição de pontos em um único ponto compõe a atmosfera fantástica da narrativa de Borges, também presente nas canções de Vitor, como em "A ilusão da casa", do disco Tambong (2000), música em que o eu lírico contempla imagens que se sobrepõem e enchem a casa, mesclando as categorias de tempo e espaço, ao afirmar que o tempo é seu lugar e sua casa:

\author{
As imagens descem como folhas \\ No chão da sala \\ Folhas que o luar acende \\ Folhas que o vento espalha \\ Eu plantado no alto em mim \\ Contemplo a ilusão da casa \\ As imagens enchem tudo \\ Vivem enquanto falo \\ Eu sei \\ O tempo é o meu lugar \\ O tempo é minha casa \\ A casa é onde quero estar
}

A veia fantástica cultivada pelos escritores latino-americanos é uma marca constante no compositor brasileiro. Inspirada no conto fantástico "O jardim dos caminhos que se bifurcam" do livro Ficções de Borges (1999), a letra da música "O astronauta lírico”, do disco Satolep sambatown (2007), mistura elementos de realidade e imaginação, resultando em um estilo surrealista que caracteriza algumas composições de Ramil:

Quero perder o medo da poesia

Encontrar a métrica e a lágrima

Onde os caminhos se bifurcam

Flanando na miragem de um jardim

4 A letra inicial do alfabeto hebraico, correspondente ao alfa grego e ao "a" dos alfabetos romanos. 
FERREIRA, Cinara e SOARES, Carlos W.

Quero sentir o vento das esquinas

Circulando a calma do meu íntimo

Entre a poeira das palavras

Subir na tua voz em espiral

Eu, astronauta lírico em terra

Indo a teu lado leve e pensativo

Transposta para a canção, a imagem do jardim de caminhos que se bifurcam é uma metáfora dos caminhos da poesia, gênero que pede a fusão entre métrica e lágrima, ou entre forma e conteúdo, síntese almejada pelo eu lírico. Interessante recordar que, para Foucault, o jardim é uma espécie de heterotopia feliz e universal, que representa a totalidade do mundo. Segundo o autor, a heterotopia tem o poder de justapor em um só lugar real vários espaços, várias localizações, incompatíveis entre si (1967), como muito bem representa Borges em "O Aleph". Portanto, pode-se supor que a canção projeta a realização da poesia nesse espaço feliz e de muitos caminhos contraditórios.

No jardim de caminhos que se bifurcam na obra de Vitor Ramil, a emblemática canção "Loucos de cara", do disco Tango (1987), parece ser uma síntese da proposta de representação heterotópica, herdada de Jorge Luis Borges, que entrecruza distintos tempos, espaços, personagens históricos e míticos, apontando que a realidade e a ficção se amalgamam:

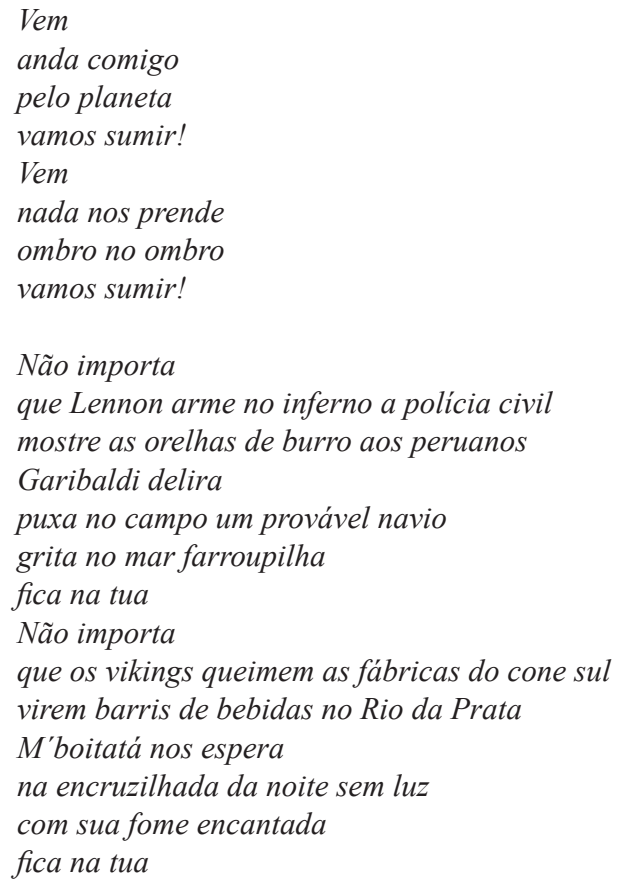

Composta com seu irmão Kleiton Ramil, "Loucos de cara" dirige-se ao ouvinte convidando-o a um passeio por heterotopias e heterocronias diversas que se sobrepõem e simbolizam a complexidade da experiência humana ao longo dos séculos. Espaços e tem- 
pos distintos existem simultaneamente e se apresentam ante os olhos do ouvinte-espectador, a quem cabe dar seus passos apesar das incongruências do caminho. Nessa canção, não se trata de representar ao homem de um espaço específico, no qual a cor local, o clima e a geografia determinam sua identidade, mas de ampliar a representação, mostrando um sujeito que anda por caminhos de um mundo heterogêneo e em constante transformação, assim como são as identidades dos que o habitam.

\section{Considerações finais}

Entrecruzando realidades distintas em que o real e o ficcional se confundem, tal como faz Jorge Luis Borges, Vitor Ramil representa esteticamente o Sul e o universo. O local e o universal dialogam constantemente em suas composições, assim como passado e presente, revelando um artista completo que oferece uma obra consistente e em sintonia com seu tempo e espaço. Nesse sentido, a literatura de Jorge Luis Borges é, conforme o compositor brasileiro declarou muitas vezes, uma grande referência e influência em sua criação artística.

A partir da análise da trajetória poética e musical assim como da proposta ensaística de Vitor Ramil, verificamos o quanto a estética do artista gaúcho, talvez pelo espaço de onde produz, propõe uma continuidade à estética de Jorge Luis Borges, escritor considerado precursor na representação de questões da pós-modernidade, que tem os espaços e seus desdobramentos como ponto central de uma reflexão sobre o presente. O sujeito pós-moderno, habitante de um lugar e ao mesmo tempo de todos os lugares, enxerga-se no espelho das canções de Vitor Ramil, assim como o leitor de Jorge Luis Borges vê-se duplicado em seus contos e ensaios.

\section{Referências}

BORGES, J. L. Ficcões. São Paulo: Globo, 1999. Trad. Carlos Nejar. . Obras completas: 1923 - 1972. EMECÉ Editores, 1974.

CHAVES, C. L. Canções, na verdade. In: RAMIL, V. Vitor Ramil: Songbook. Belas Letras, 2013, p. 267-304.

FISCHER, L. A. Nesta rua passa o universo. In: RAMIL, V. Vitor Ramil: Songbook, Belas Letras, 2013, p. 7-13.

FOUCAULT, M. As palavras e as coisas: uma arqueologia das ciências humanas. 9. ed. São Paulo: Martins Fontes, 2000.

FOUCAULT, M. De outros espaços. (Conferência proferida por Michel Foucault no Cercle d'Études Architecturales, em 14 de Março de 1967. Traduzido a partir do inglês por Pedro Moura, com base no texto publicado em Diacritics; 16-1, Primavera de 1986). Disponível em: <http://historiacultural.mpbnet.com.br/pos-modernismo/Foucault-De Outros_Espacos.pdf>. Acesso em: 30 jul. 2018.

OLMOS, A. C. A. A narrativa fantástica de Jorge Luis Borges. Univesp. 2016. Disponível em: < univesp.br/novidades/a-narrativa-fantastica-de-jorge-luis-borges>. Acesso em: 25 set. 2016.

RAMIL, V. A estética do frio: conferência de Genebra. Satolep, 2004. . A paixão de V segundo ele próprio. Som Livre/RBS Discos, 1984. 
FERREIRA, Cinara e SOARES, Carlos W.

. À beça. Capacete Records, 1995.

Délibáb. Direção do documentário délibáb documental: César Custodio, Satolep, 2010.

Estrela, estrela. Polygram, 1981.

Ramilonga: a estética do frio. Satolep, 1997.

. Satolep. Cosac Naify, 2008.

. Satolep sambatown. MPB Discos/Universal, 2007.

. Tambong. Satolep, 2000.

. Tango. EMI/Odeon, 1987.

SÁBATO, E. Nosso universo maravilhoso. Rio de Janeiro: Livraria El Ateneo do Brasil, 1960.

ZWANCK, M. I. Posdata a la escritura contemporánea: Borges, Saramago y otros autores. Buenos Aires: Áncora, 2008.

Recebido em: 30/07/2018 Aceito em: 04/09/2018 